\title{
Metaphor, Irony and Sarcasm in public discourse
}

\begin{abstract}
In public political discourse, figurative expressions used by one participant are often followed up and 'countered' by other participants through ironical and/or sarcastic allusions or quotations, which are aimed at denouncing the preceding version and/or deriving a new, contrarian conclusion from it. What is the relationship between the figurative template expression and its ironical or sarcastic variants? Using data from a corpus documenting 25 years of debate in Britain about the nation's place at the heart of Europe, this paper investigates the interplay of metaphor, irony and sarcasm in public discourse. We show that the 'discourse career' of this metaphorical slogan bifurcates into two strands, i.e. an affirmative, optimistic use vs deriding and ridiculing uses that depict the heart of Europe as diseased, dead, non-existent or rotten. It is argued that discourse participants need to retain the optimistic template version as a reference point in discourse memory to achieve the intended ironical and/or sarcastic effects, and that the latter are essential to keep the metaphoricity of the slogan 'alive'.
\end{abstract}

Keywords: discourse history, echoic utterance, follow-up, irony, metaphor, metarepresentation, quotation, sarcasm 


\section{Introduction}

The public debate surrounding the referendum on the United Kingdom's exit ("Brexit") from the European Union (EU) has witnessed a revival of sorts for a metaphorical slogan about Britain's relationship with the EU that had already been declared 'dead' several times, i.e. the contention that Britain is or should (not) be at the heart of Europe. Public voices opposing Brexit have used it as a slogan to suggest that Britain would be better off and should stay in the EU, as the following examples show:

(1) [The CEO of Ryanair] Mr O'Leary told The Independent: "If you keep Britain at the heart of Europe we are more likely to see more effective reform." (The Independent, 24/02/2016)

(2) [The former Labour Prime Minister] Blair said [...] it was Britain's "destiny" to place itself right at the heart of Europe. (Daily Express, 11/03/2016)

(3) [US President] Barack Obama has made clear that the British relationship is valued in part because of the UK's place at the heart of Europe. (The Guardian, 25/06/2016)

On the other hand, Brexit supporters (or "Brexiteers", as they were nicknamed) have used the metaphor to attribute to its figurative referent negative characteristics, such as lack of viability, health, or relevance:

(4) UK trade data and the rotten heart of Europe. (Capital \& Conflict, $11 / 03 / 2016)$ 
(5) David Cameron, seeking a looser new UK membership agreement with the EU [...] [should] study closely the unstoppable process of integration that has once again been shown to be at the heart of the EU, and reflect that the only viable British relationship with the EU is one that keeps this country a healthy distance from the whole doomed European project. (The Daily Telegraph, 14/07/2015)

(6) With the UK on the brink of a new era of prosperity free from Brussels rule, [...] the 19 country currency zone [=eurozone] at the heart of the failing EU project only grew by 0.3 per cent in the last quarter, just half the rate of the UK (Daily Express, 30/07/2016).

The use of the 'heart' concept to in statements conveying a negative evaluation of the EU in the latter examples may seem odd at first sight. Given the positive connotations of 'heart' in the ubiquitous phrase (at) the heart of, as well as in other idiomatic and proverbial sayings in English, ${ }^{1}$ its assertive use, as in examples (1) - (3), seems much more likely. It is conventional and not metaphorically very vivid, with the 'heart' element denoting first and foremost the notion of 'centrality', and only weakly connoting a 'body'-related meaning. ${ }^{2}$ So, what happens when the 'heart' element in the slogan is reinterpreted as a rotten

1 Niemeyer (2000) has shown that the conceptual motivation of HEART-based idioms and metaphors in English is predominantly positively biased, e.g. by qualifying the respective referents as essential, autonomous, valuable, and alive. Negatively biased idioms (cold heart, heart of stone) appear to be less frequent and restricted in usage.

2 See Shorter Oxford English Dictionary 2002, vol. 1: 1213 and Roget's International Thesaurus, 1996: 143. 
or unhealthy organ of a failing organism? This question gains a discoursehistorical dimension when we take into consideration that the slogan had its 'obituary' written as early as in 1994:

(7) One British metaphor, at least, has ceased to beat. John Major said in Bonn in March 1991, that he wanted to put Britain "where we belong, at the very heart of Europe". [...] An editorial [...] earlier this year suggested that if Mr Major wanted to be at the heart of Europe, it was, presumably, as a blood clot. (The Independent, 11/09/1994).

In this passage, the author quotes an earlier statement by the then Conservative Prime Minister J. Major from three years earlier, in which Major had used the heart of Europe phrase to make an optimistic promise of a constructive engagement with the EU. Now, in 1994, his good intentions are sarcastically denounced by the Independent journalist through combining the quotation with the notion of a blood clot that could only kill the heart of Europe. This sarcastic denunciation in the last sentence confirms the verdict in the introductory statement about the heart-metaphor itself having died (ceased to beat): thus both the metaphor and its content are merged into one (allegedly) dying entity. As a metaphorical blend (Fauconnier and Turner 2002, pp. 126-131), ${ }^{3}$ the passage is

3 The "blend' here is understood in the sense of a "double-scope network of conceptual integration, which allows for the combination of conflicting "mental spaces" (Fauconnier 1994) to generate an emergent new construction that need not be factually or logically consistent. This concept of "blend" is different from that developed by Pálinkás (2014) 
so elaborate that its communicative effect must contain 'added value' to be worthwhile the extra comprehension effort by the reader. This is indeed the case: example (7) not only reproduces and extends the metaphor but provides a sarcastic commentary on the state the British EU-debates - at a time when "Brexit" still seemed a long way off.

This article investigates the interplay between metaphor and sarcasm as well as irony with reference to a real-life usage corpus documenting the development of the slogan Britain at the heart of Europe over 25 years. Its aim is threefold: first, we will map out the 'discourse career' of this metaphorical slogan as a series of re-contextualisations that have affected its evaluative bias and resulted in two main opposite usage versions; secondly, we argue that even its ironical and/or sarcastic uses still presuppose the optimistic usage template, so that in a sense, the latter has never disappeared completely from the conceptual "scenario" that is evoked by the metaphor, and thirdly, we propose a distinction between ironical and sarcastic uses that is based on their relationship to the preceding 'template' use (rather than treating sarcasm just as an 'insulting' form of irony).

\section{Metaphor, irony and sarcasm as "figures of speech"}

Irony, sarcasm and metaphor used to be siblings in the family of rhetorical "figures of speech", especially in the analysis of political rhetoric (Charteris-Black 2014: 45-49). H.P. Grice, in his essay from 1975, "Logic and Conversation",

who analyses irony in general as a folk theory phenomenon based on blendings of "reality" and/or "irreality spaces". 
grouped metaphor and irony (with sarcasm implicitly subsumed in the latter) together as acts of flouting the maxim of quality (or truthfulness) and thus generating conversational "implicatures". Metaphor and irony/sarcasm could be used together "by imposing on the hearer two stages of interpretation, i.e. first by recognising a "categorial falsity" as metaphorical, e.g. addressing a person as you are the cream in my coffee to convey the meaning pride and joy, and secondly, by comparing this meaning as "contradictory" with the shared background knowledge that the speaker despises the addressee, which leads to the irony or sarcasm reading that the speaker is in fact insulting the addressee along the lines of saying you are my bane (Grice, 1989: 34).

Since then, metaphor and irony, with sarcasm in its wake, seem to have gone their separate ways, engaging, as they have done, in affairs with embodiment, relevance, pretence and salience. ${ }^{4}$ Irony's 'implicit negative commentary' character has been analysed as an "echoic" utterance, in which "the speaker dissociates herself from the thought she is echoing" (Wilson and Sperber 1992: 60; see also Sperber and Wilson 1981; Wilson and Sperber 2012). Further approaches have viewed irony as an implicit distancing comment on the "staged" or "pretended" utterance by an "injudicious person speaking to an uninitiated audience" (Clark and Gerrig 1984: 121; see e.g. also Kumon-Nakamura, Glucksberg and Brown 1995, Recanati 2004: 77-78). Experimental studies have focused on specificities of the identification and (speed of) processing of irony

${ }^{4}$ For a reformulation and extension of the Gricean approach to cover irony phenomena highlighted by critics see Dynel 2013. 
and sarcasm vis-à-vis metaphor. Colston and Gibbs (2002), for instance, highlight the extra cognitive effort of metarepresentational (Sperber 2000) reasoning involved in irony. Giora $(1995,2003)$ and Giora et al. $(2015 a, b)$ stress the importance of "salience" and, more recently, of "defaultness" as determining processing speed and goodness judgments for irony and sarcasm, with a focus on a type of negated statements that are routinely interpreted as sarcastic, e.g. '[quality $\mathrm{X}]$ is not his forte/ most distinctive feature').

Of particular interest for the investigation of examples such as the slogan Britain at the heart of Europe are Partington's $(2007,2011)$ studies of "phrasal irony", which analyse the implied "reversal" of a customary evaluative bias of well-known phrases, such as "Y has made a good job of discrediting himself", where the default implication, i.e. that the referent of "a good job" is good, is turned on its head by being applied to a negative referent action, thus "discrediting" it with ironical effect (Partington 2011: 1794). On the basis of empirical corpus data, Partington shows that such "reversed" versions can become a recognised and popular usage in their own right (Partington 2007: 1551-1553; 2011: 2788-2789). Something comparable seems to have happened with the phrase at the heart of (Europe) in our examples (4) - (7), but they differ from implicit phrasal irony in that they a) explicitly denounce the default reading and b) involve an evaluative reversal that concerns not only the standard primary meaning of the phrase, i.e., 'heart-as-centre', but also its more strongly metaphorical meaning, i.e., 'heart-asbody organ'. They thus exhibit a complex inferential structure (not to be confused with a psychological account of comprehension phases), which includes: 
- A basic, weakly metaphorical extension: 'heart' -> 'centre', which underlies the customary interpretation of the idiomatic phrase at the heart of...;

- A more strongly metaphorical mapping: 'heart' -> '(central and most important) body organ', connoting a default assumption of the healthiness of the respective (metaphorical) 'organism', which underlies the optimistic use of the slogan Britain at the heart of Europe;

- An ironical reversal of the positive/optimistic connotation by way of introducing a contradictory element to the 'healthiness' assumption (e.g. blood clot, rotten heart) that turns the pragmatic effect of an optimistic promise into a denunciation or warning;

- A further, specifically sarcastic conclusion, i.e. that preceding uses of the optimistic version have been proven wrong and can therefore be ridiculed as incompetent or insincere.

In the following section, we investigate how this multi-layered inference hierarchy has emerged and spread in the British discourse community.

\section{The heart-of-Europe metaphor in British public discourse 1991-2016} The basis for the following discourse-historical sketch of the development of the slogan Britain at the heart of Europe is a multilingual corpus of figurative press texts on EU-politics (EUROMETA) that goes back to 1989 and reaches until 
September 2016. ${ }^{5}$ The British sample alone includes 236 texts that contain 272 tokens (i.e. lexical items from the 'heart' domain that cannot be accorded a literal meaning). ${ }^{6}$ The sample thus yields $9-10$ texts per year on average, with peak occurrences (>20) in some years $(1991,1995,1999,2016)$. However, as the search did not cover all newspapers for all years, a statistical analysis is not possible: our data can only be interpreted as representing the range of types of uses, not their actual frequencies. Hence, also the selection of examples discussed here is not representative in a statistical sense but focuses on the subsection of ironical and sarcastic uses, with the aim to shed light on the pragmatic factors underlying the resuscitation, ironical reversal and further sarcastic exploitation of the metaphor.

In a first broad overview, assertive-optimistic, negative-deriding, and neutralquotative usage types each account for one third of the documented cases $(32 \%$, $34 \%, 32 \%$ respectively). However, this count is based on the overall stance of the respective text passages, and is therefore deceptive insofar as many of the negative-deriding uses, such as that in example (7), both quote a preceding positive or neutral use and then extend the metaphor in order to reverse its bias

${ }^{5}$ Overall, EUROMETA is currently 599.000 words large and has more than 2400 separate text entries. For a general overview and analysis of EUROMETA see Musolff 2004a; for detailed analyses of the history of the Britain at the heart of Europe slogan in comparative (i.e. British-German) and discourse-historical perspectives see Musolff 2004b, 2013.

${ }^{6}$ The British sample is over 360.000 words large, with the 'heart-body-health' domain alone accounting for 105.117 words. It is drawn from a broad spectrum of newspapers and magazines (print and online versions), specifically Daily Express, Daily Mail, Eastern Daily Press, Financial Times, New Statesman (previously: New Statesman \& Society), The Daily Telegraph, The Economist, The Guardian/Observer, The Independent, The Northern Echo, The Scotsman, The Spectator, The Sun, The Sunday Times, The Times. 
and achieve an ironic effect. Many of the assertive and neutral uses also quote or allude to preceding uses, which originate either in the speech of politicians or in other media sources (i.e. media quoting other media). This means that more than three quarters of all texts in the sample both "use" and "mention"/metarepresent (Sperber 2000) the heart of Europe metaphor.

These derived uses can be characterised as "follow-ups" in the broad sense of Fetzer and Weizman (2015: xii), i.e. communicative reactions to preceding utterances, which can "span across longer sequences within the same discourse and be assigned the status as an object of talk", giving rise to further reevaluations of their pragmatic bias. In contrast to follow-ups in face-to-face conversations, the follow-ups of public discourse can be delayed, even by several years. In example (7), for instance, the journalist's comment follows up Major's use of the slogan from three years before and resuscitates its metaphoricity by punning on the source-domain through use of heart-related phraseology (ceased to beat), and by using a further (quoted) pun to achieve a recognition-plus-revelation effect that could be paraphrased as: 'being a blood clot at the heart of Europe - that is what Major really wants to be in EU politics.' Together with the preceding uses, follow-ups constitute a kind of virtual conversation, in which the metaphorical slogan becomes the object of continuous reinterpretation (Musolff 2011: 202). 
The discourse career of the Britain at the heart of Europe slogan ${ }^{7}$ was launched in 1991, in the speech by John Major referred to in example $(7),{ }^{8}$ which he delivered in Bonn, Germany, at the invitation of the Christian Democratic Party. He promised:

(8) Our government will work at the very heart of Europe with its partners in forging an integrated European community. (The Guardian, 12/03/1991)

Initially, Major's metaphor was mainly interpreted in the 'heart as centre' sense, i.e. as part of a promise that indicated a decisive break with the "Eurosceptic" stance of his Prime Ministerial predecessor, M. Thatcher. The well-respected, liberal-leaning British news magazine, The Economist, took the new policy for granted: "Of course Britain should be at the heart of Europe whenever it possibly can, for that is where the decisions that affect many British interests are being taken" (The Economist, 23/11/1991), which seems to have been exactly what Major wanted to convey. ${ }^{9}$ The Tory-critical Guardian assessed it as an astute, if ambiguous, political move, because it left "supporters and critics of Euro-

7 The notion of a metaphor's "discourse career" is not to identical with Bowdle and Gentner's (2005) notion of the "career of metaphor", which captures the process of metaphor "conventionalization", i.e. as a shift from the comparison to the categorization type of mapping. As will be seen shortly, the discourse career of the slogan Britain at the heart of Europe seems to involve, if anything, a series of de-conventionalizations.

8 The British sample of the EUROMETA corpus includes examples of the heart of Europe from before 1991 but they do not include promises of Britain being "at" or "close" to it.

${ }^{9}$ Major retrospectively explained the intended meaning of his slogan as expressing his government's "self-evident" wish to "improve our profile in Europe" (Major, 2000: 268269). 
federalism claiming [that Major] had signalled a decisive shift in their direction" (The Guardian, 13/03/1991). Later that year, however, after negotiations for a new EU Treaty led to his government's "opt-out" from the planned common EUcurrency, Major's parliamentary opponents questioned his closeness to Europe's heart by contrasting his speech with the negotiation results. The Labour leader, N. Kinnock, asked him how he could "claim to be at the heart of Europe when, because of his actions, our country is not even part of the key decisions that will shape the Europe of the future", and the leader of the Liberal Democrats, P. Ashdown, alleged that Major had "condemned this country to be semi-detached from [the heart]" (Hansard 11/12/1991). The slogan's metarepresented meaning in such criticisms clearly still hinged on the heart-as-centre' interpretation.

During the following years, Major's statement was quoted time and again as a point of reference for his officially positive stance on Europe, with most commentators tacitly assuming that being close to the EU's heart was desirable. This perspective changed, however, fundamentally when, in August 1994, the French and German government parties published proposals for further political EU integration. They envisaged a division of the Union into an "inner core" or "circle" of member states committed to faster socio-economic integration, and several "outer circles" of less committed states, to which Britain belonged. Without negating explicitly Major's slogan, the exclusion of Britain from the EU's "inner core" effectively undermined any pretence of being at its heart. Major rejected the proposals within days, and the pro-EU-leaning Independent newspaper pointed out his dilemma of being too close to the centre of EU policy 
for his own party's liking and not sufficiently close enough in the eyes of France and Germany with a pun on the idiom 'out on a limb'10:

(9) He wanted Britain to be at the heart of Europe. Yet too often he found himself alone at the end of a limb. (The Independent, 08/09/1994)

Shortly after, the Independent published the even more drastic verdict on Major wishing to be the blood clot at Europe's heart, quoted in example (7) above. By re-contextualising the phrase at the heart through referencing a heart attack, the writer resuscitates the latent corporeal aspects of the 'heart' source concept of Major's slogan. In a similar vein, the Daily Telegraph (08/09/1994) portrayed his heart of Europe-ambition as "challenged", the Guardian (09/02/1995) called it "less than full-blooded" and a former EU official B. Connolly published a book alleging corruption an gross incompetence in the EU administration under the title The Rotten heart of Europe, which was reviewed and advertised across the whole spectrum of the British press, and, predictably became a favourite with EUsceptics. ${ }^{11}$ Further negative body-referencing diagnoses of the health of Europe's heart followed, e.g. that Major's policy was "blocking its arteries" (former Prime Minister E. Heath, quoted in The Daily Telegraph, 21/06/1996), that the "heart of

10 Brewer's Dictionary of Phrase \& Fable (1999: 864): "Out on a limb. Isolated, stranded or cut off, as an animal at the end of a branch of a tree". The formulation "at the end of a limb" is perhaps a mix-up triggered by the 'END OF X' connotation.

11 See Connolly 1995; for positive or neutral reviews, often with further puns on the rotten heart metaphor version, see The Daily Telegraph, The Economist, The Guardian, The Independent, The Spectator, The Times (May-November 1995). Connolly's catchy title is being recycled up to the present day, see example (4). 
Europe" was "diseased" " (former Chancellor of the Exchequer N. Lamont, quoted in The Guardian, 10/10/1996). By the time of the following general election, the Guardian augured that Major's 'Britain at the heart of Europe' fudge" had destroyed his authority (The Guardian, 17/041997).

Despite the slogan's ambivalent success during the Conservative government, their Labour successors under Tony Blair were keen to claim Britain at the heart of Europe as an optimistic slogan for themselves (The Guardian 10/06/1997). However, Labour usage reached its sell-by date even faster than Major's, as the Guardian pointed out:

The litany passes from government to government. A Britain at the heart of Europe. We'll hear the chant 1,000 times again this month [...]. But hold the stethoscope and listen carefully, for the heart has some curious murmurs. [...] [The issues actually discussed by the officialdom of Brussels] bear no relationship to the British "debate", hearts, livers, gall bladders and all. (The Guardian, 01/12/1997)

In this example, the dismissive characterisation on the slogan as a "litany" or "chant" is escalated, as it were, by a metaphor extension (stethoscope, heart's murmurs), that leads up to the contemptuous punch-line of connecting the "heart" debate with a list of 'lower' body-organs, "livers, gall bladders and all", which highlights its supposed EU-political insignificance. From now on, drastic denunciations of the heart of Europe by way of grotesque body-references 
became fashionable, e.g. during the 1998 nepotism scandal, which inspired large sections of the British press to compete for coming up with the most damning diagnosis:

(11) the rotten heart of Europe will never be cleaned out. (The Sun, 17/03/1999)

(12) [markets fear] a political vacuum at the heart of Europe (The Guardian, 17/03/1999)

(13) $[\ldots]$ changes in personnel will not be enough to stop the rot at the heart of the EU (Daily Mail, 17/03/1999)

(14) [...] abruptly the heart of Europe got sick. (The Economist, 18/03/1999) [...] a hole suddenly opened up at the heart of the European Union. (The Independent, 21/03/1999)

The media also mocked the slogan by linking it to current real-life body- and illness-related topics. During the foot and mouth epidemic of 2001, for instance, The Guardian derided Labour's EU-credentials by linking other EU member states' views of Britain to the recently imposed public hygiene measures: When the time $[\ldots]$ comes for Tony Blair to make good his promise to be 'at the heart of Europe' $[\ldots]$ the neighbours might offer him a look of 
pity and a cup of sweetened tea — but only after he has wiped his feet in a trough of disinfectant. (The Guardian, 04/04/2001)

In a conflict with France over the refugee camp at Calais, the Sun mocked the PM by inventing a European 'response' gesture: Tony Blair says he wants Britain to be at the heart of Europe. Well it looks this morning as if Europe is showing us its backside." (The Sun, 03/09/2001).

Compared with the assertive or neutral uses and the non-metaphorical rejections of the slogan, such mocking inversions remained a minority (amounting to only $10-15 \%$ in our sample) but were sufficiently frequent to form a continuous substrand that generated its own follow-ups and survived following government changes (Musolff 2013: 240-248). From autumn 2014 onwards, i.e. in the run-up to the 2015 election campaign, the public debate about a possible referendum on Britain's EU-membership became the main thematic context of the slogan's use. Once again, denouncing the heart of Europe became a popular pastime among journalists (see examples 4-6), despite a few 'rear-guard' optimistic uses by proheart of Europe voices including Major and Blair, whose historic promises were still explicitly remembered - as having become obsolete. ${ }^{12}$ After the referendum, which yielded a pro-withdrawal result, the heart of Europe was once more

${ }_{12}$ See The Independent, 22/06/2016 and Daily Express 11/03/2016. 
pronounced dead, on account of the referendum having "plunged a dagger" into it (The Independent, 26 June 2016). But even after this latest death announcement, the heart metaphor proved too attractive to be left alone, with the Daily Telegraph deriding the EU Commission President J.-C. Juncker for daring to criticize the UK's insistence on limiting free movement across EU as "displaying a deep contempt at the heart of the European project for the collective will [...] of the people" (The Daily Telegraph, 23/08/2016).

The early phase of the referendum debate saw the publication of one text that provides a remarkable usage example of the Britain at the heart of Europe slogan and is of crucial significance for the distinction or ironical and sarcastic metaphor uses. In autumn 2014, at a time when Cameron's government first mooted plans for negotiations with the EU about "reforms" (which were expected to yield so many advantages for Britain that staying in the EU would remain attractive for a majority of the electorate and thus produce an anti-Brexit vote), the Financial Times published an article that purported to give a verbatim account of a conversation between Cameron and Juncker. Its attention-grabbing title was, "David Cameron opts out to keep Britain at heart of Europe" (Financial Times, 30/10/2014). Towards the end of the dialogue, Juncker asks Cameron what the EU would gain from a deal that fulfils all the British demands:

Jean-Claude Juncker: So just to clarify. Aside from not joining the euro, you want to limit the free movement of people, cut the power of the European Court and the European Parliament... 
David Cameron: And since we are opting out of so much, we should pay less too.

Jean-Claude Juncker: This is quite a list of demands, David. What do we get in return?

David Cameron: A Britain at the heart of Europe, of course. (Financial Times, 30/10/2014)

When read in isolation, Cameron's final response might conceivably be understood as promising a positive relationship between his country and the EU, similar to the pledge given by Major in 1991 (example 8). However, in the discursive context of the article, such an interpretation is unlikely. At the level of the conversation, Cameron's answer is disingenuous or just provocative, given that he has already made so many demands for opting out of central EU policies. Within the dialogue, he is presented as wanting less cooperation, not more; therefore, his reassurance that Britain will be "at the heart of Europe" sounds hollow.

When considering the likely real-life context for the text reception, however, Financial Times readers could not take the answer at its face value, i.e. as a simple lie or a provocation. In the first place, they were aware of the real-life fact that in the negotiations with the EU, the Prime Minister had linked his demands with a possible referendum about the UK's withdrawal from the EU. Against this background, the final answer in example (18) could only plausibly be read as 'giving away' the real Cameron's minimalist plans for British engagement with the 
EU. To arrive at such an ironical comment reading, readers had to notice the fictitious character of the supposed conversation. In this they were helped by a number of co-textual signposts, e.g. the lack of any journalistic or official source for the report, the paradoxically formulated headline (opt out ... to keep at heart), and the grotesquely inadequate admission by the "Cameron" character that it would not "break his heart" if the UK left the EU - but only "ruin his tea". As a result, readers were unlikely to conclude that "Cameron's" final answer was real; however, as a fictitious one it only made sense as an ironical metacommunicative comment on the slogan's discourse career, i.e., a disillusioning echo of its former, optimistic uses.

\section{Discussion}

On the basis of a 25-year spanning overview, we can summarise the discourse career of the slogan Britain at the heart of Europe as a continuous strand of public debate, sustained by reformulations, allusions, meta-communicative comments and follow-ups. The continuously recycled metaphorical slogan has provided a thematic focus and created discursive coherence of this debate, whilst at the same time staying flexible enough to allow for variation as regards the differential highlighting of specific source domain aspects to support opposing stances. Some politicians employed the metaphor to defend a stronger British engagement with the EU whilst others employed it to argue in favour of a withdrawal. As a consequence, the metaphor, together with its derogatory 
variants of the unhealthy/dysfunctional heart, has become an index of the speakers' (EU-)political allegiances.

Whilst the positive-assertive uses show little variation, we can distinguish two main "scenarios", i.e. framing types (Musolff, 2006: 32-36) for the metaphorical elements in the Britain at the heart of Europe slogan among the derogatory uses. They concern either Britain's position vis-à-vis the EU heart (e.g. being detached from heart/arteries, outside the heart, on the periphery of the heart, elusive heart; at the end of/out on a limb) or the unhealthy condition of the EU heart or arteries (e.g., blocked, cracked, dead, dirty/smelly, hollowed-out, rotten, sick/ill/diseased, and characterizations such as blood clot/flaw/hole/split/time bomb/vacuum at the heart, heart crisis, heart of stone, no heart, time-bomb at the heart, threatened by euro-sclerosis,). Together with the juxtapositions of the heart with 'low' or 'embarrassing' body parts or hygiene issues (backside, gall bladder, liver, wipe feet, see examples $10,16,17)$, the second scenario type provided ample opportunities for critics to sarcastically denounce the notion of 'Britain at the heart of Europe' by resuscitating the source aspect of the 'heart' concept and highlighting a supposed mismatch between its tacitly assumed positive bias, i.e. healthiness, and an alleged poor or even catastrophically bad state of (metaphorical) health of the target concept (EU/EU policy). This sarcastic denunciation effect is not subtle but drastic and functions as "implicational impoliteness" (Culpeper, 2011: 165-167). It is often aimed at a specific politician's or group of politicians' public "face" by attacking their presupposed (quoted or 
alluded to) promise of (or demand for) a 'Britain at the heart of Europe' as hypocritical, dangerous or irrelevant.

Before we can explicate further the relationship of ironical and sarcastic uses, we need to account for their (shared) relationship to metaphor. In the absence of experimentally controlled comprehension data for the actual reception of our texts, it is difficult to give a psycholinguistic account. However, on the basis of existing research, hypotheses can be formulated about the general conditions for the comprehension of ironic and/or sarcastic uses of metaphor. Following Giora (2003: 3), we posit two main phases in comprehension processes, i.e. initial activation, "in which contextually appropriate and salient meanings are activated", which is followed by integration, "in which the activated meanings are either retained for further processes or suppressed as conceptually disruptive". The basic metaphor identification for the 'heart'-concept in Britain at the heart of Europe is likely to belong to this initial activation phase because it will cost no extra processing time compared with a more literal alternative (e.g. ... at the centre...). This hypothesis is based on widely corroborated evidence for conventional metaphor comprehension being as fast and quasi-automatic as non-figurative comprehension (Gibbs 1994, 2007; Gibbs and Colston 2012; Giora 2003).

Basic irony and/or sarcasm recognition should also belong in the initial phase, insofar as the contradiction between echoed or pretended meaning of the explicit use and the intended disassociation can be assumed to be salient in political discourse, given the shared background knowledge about the political stances of 
the respective speakers. The integration of ironical or sarcastic interpretations into confirmed readings, however, necessitates a further processing phase for working out relevant implicatures. ${ }^{13}$ The mock-dialogue in example (18) provides a prototypical case which, according to Giora (1995), forces the reader/hearer to "entertain both the explicit and implicated messages so that the dissimilarity between them may be computed" (1995: 241). After demanding a long list of British opt-outs from all the main EU policies, the "Cameron" character promises "A Britain at the heart of Europe" in return. As a real-world statement this utterance is implausible, but as a fictional construction it can be read as an ironical comment on the parallel histories of minimalist UK engagement with Europe and the pretence to be at its heart.

The more "sarcastic" examples such as (7) - (17) share with this irony case the "echoic" allusion to a preceding use, which assumed the desirability of being close to the (healthy) heart of Europe. Without this allusion, the denunciation or ridiculing effect cannot take place. Pointing out the ill health or death of a heart can only be understood as an implicit meta-communicative criticism if the speaker/writers' and hearers/readers' shared knowledge includes an awareness of a preceding utterance that asserted healthiness as a salient aspect, in the sense of Giora's "graded salience" hypothesis (Giora 2003). In two recent publications on sarcasm comprehension Giora et al. (2015a, 2015b) have refined the "graded salience" theory of figurative language

${ }^{13}$ See also Partington 2007: 1567, for such a distinction of two "stages" in irony comprehension. 
comprehension by analysing the results of experiments which show that default non-salient sarcasm interpretations of statements such as ' $X$ is not his forte/most distinctive feature' are processed faster than non-default salience-based interpretations (2015a: 192-194; 2015b: 308). As a result, they now see defaultness as an overarching principle that organises salience hierarchies. As far as our data are concerned, the salience factor as such is sufficient to analyse an ironical allusion: in cases such as (18), the (unattributed) preceding utterance of the optimistic slogan version is clearly presupposed because otherwise the interpretation of the actual utterance in the given context is highly implausible; in other, less elaborate cases such precedents are explicitly quoted to remind readers of their salience.

However, with regard to the negatively evaluative metaphor scenarios that provide the conceptual platform for sarcasm, the defaultness principle is of crucial importance. In addition to alluding to a preceding, positively-optimistically biased use and to taking a distancing or contradicting stance (which, if made implicitly, renders irony), they also implicate that the preceding speakers have (more or less) naively followed the default assumption at the level of the metaphor source scenario. They believed that 'being close to a healthy heart is a good thing', whereas the actual speaker knows on the basis of an alleged scandal or revelation that this positive-optimistic scenario is wrong and needs to be replaced by a contradictory, negative context of 'heart failure', 'illness', 'rottenness' etc. In the irony case, on the other hand, such an emphatic contrasting of default and actual scenario is not necessarily assumed: the ironic 
disassociation of the actual speaker from the preceding use can be related to any contextual aspect, not only to the contradiction/subversion of the default bias of the metaphor.

In terms of comprehension, the confirmed understanding of sarcastic implicatures can only be allocated to Giora's "integration phase", in which the contradicting scenarios can be compared against each other, to yield a denunciation of the preceding use of the slogan Britain at the heart of Europe. Summarising these implicational steps, we can conclude that in order to achieve the sarcasm reading of a metaphorical slogan such as Britain at the heart of Europe, recipients need to adduce evidence from the textual environment and their wider socio-historical knowledge, in order to:

a) recognise the global adversarial character of the actual speaker's use of the slogan (e.g. on the basis of the author's party- and EU-political leanings);

b) resuscitate the organic source scenario of the metaphorical slogan together with the positive bias ('healthy heart') of its preceding use(s) and contrast it with the negative bias of the recontextualised scenario (e.g. 'illness', 'death'; or otherwise negatively connoted body parts: 'backside', 'gall bladder');

c) interpret the mismatch between the preceding and actual utterances as proof of its speaker's incompetence/naivety (from the actual speaker's viewpoint) in relying on the default scenario of a 'healthy heart'. By juxtaposing the echoed or pretended speaker's 'healthy optimism' with a 
drastic 'illness'/'death' scenario, the actual speaker's communicative intention is interpretable as aiming at a put-down and/or disqualification of the preceding speaker's competence.

\section{Conclusion}

This paper has studied the interplay of metaphor, irony and sarcasm in public political debates by following the discourse career of a particular metaphorical phrase that gained prominence as a Euro-political slogan in 1991 and has since been in continuous use: Britain at the heart of Europe. Its medium/long-term follow-ups typically combine a metarepresentation (by way of quotation or allusion) with evaluative comments, many of which take the form of metaphor extensions and variations. Of particular interest for us have been examples in which the metaphor is reformulated in such a way as to ironically question or sarcastically denounce its initial function as an optimistic promise (of Britain's constructive engagement with EU policies). As a first result, we can note that the opposite versions have been continuously in use for 25 years, with positive uses typically reiterating the 'template' version from 1991, which presupposed the highly conventional, only weakly metaphorical 'heart as centre' interpretation. The main implicature of the resulting scenario can be paraphrased as follows, 'it is desirable to be at the centre of X (in order to have influence on X's decisions etc.)'. 
Ironical and sarcastic uses, on the other hand, presuppose a contradiction between this optimistic template scenario and context aspects that are shared knowledge of speakers and hearers. In the case of sarcastic uses, this discrepancy is highlighted through a resuscitation of the organicist connotations of the 'heart' concept. This resuscitation is triggered by a reversed scenario, in which 'illness', 'death' or other negatively connoted body-related concepts are made salient. The main implicature of this scenario can perhaps be paraphrased as, 'it is highly undesirable to be close to the dysfunctional central organ of $X$ '. Arguably, such sarcastic reformulations have done more for the survival of the slogan in discourse history than its repeated reassertion or metarepresentation could have achieved. The conventional optimistic scenario of a desirable closeness to the 'healthy heart' may be the default version of the metaphor underlying the slogan, but its nonconventional debunking by way of catastrophic illness scenarios or grotesque combinations with other body organs helps to resuscitate its metaphorical vividness and communicative attractiveness. On the evidence of the continued usage of both scenario strands in the corpus data, we can confirm our hypothesis of a bifurcation of the slogan's discourse career into two main scenarios: 1) the 'heart as (healthy) centre'-based scenario suggesting a promise of or demand for Britain's closeness to the EU and 2) the 'heart as sick organ'-scenario that helps to advocate maximum distance.

Both the ironical and sarcastic subversions of the optimistic promise scenario depend on a discourse-historical awareness (if not precise memory) of its preceding use on the part of the hearer/reader. The ironical disassociation or 
sarcastic denunciation effects, which we observed above, cannot be achieved without the hearer/reader comparing the use by the actual speaker with a contrasting preceding use. In the irony example (18), it is left to the reader to work out that the prima facie nonsensical utterance of the slogan by the "Cameron"-character functions as an ironical comment on (unspecified) preceding uses that are exposed as hollow promises. In the sarcasm examples, where preceding speakers are often explicitly named so as to enhance the denunciation/face-attack effect, the preceding version use is revealed as woefully incompetent or naïve, in view of the actual speaker's certainty about the heart of Europe's illness, death etc. In rhetorically highly elaborated cases such as examples (7) and (10), the metaphor scenarios' extension-cum-inversion can include explicit comments on its discourse career, e.g. criticism as a "litany", "chant" or a metaphor that has "ceased to beat". Journalists, as a specialised subgroup of metaphor-users and -interpreters, operate a detailed discoursehistorical memory and have a professional interest in reminding their readers of it as well as inviting them to share their more or less critical evaluation of it. This communicative purpose can only be met if the readers combine metaphor, irony and sarcasm comprehension. In real-life discourse, metaphor and its subversive siblings apparently still like to gang up - with and against each other. Regarding the third research question about differences between ironical and sarcastic uses of metaphor, the data from our sample suggest that the latter are not just a stronger, more polemical or interactionally more face-challenging subtype of the former. Sarcasm shares with irony the presupposition of an 
opposing preceding utterance. But whereas the ironical implicature can be inferred on the basis of any new context aspect that creates a mismatch between the actual utterance's surface meaning and the (echoed or pretended) preceding use, their sarcastic reversal appears to depend on contradicting the metaphor's default version, i.e. the optimistic 'heart as healthy organ' scenario. Furthermore, this contradiction is not necessarily tacitly inferred, as in irony, but it can be made explicit. However, these tentative conclusions may only be pertinent to our sample; hence, more research is needed to show whether or not they apply to other cases of sarcastic reformulations or to sarcasm in general. 


\section{References}

1. Bowdle, Brian F., Gentner, Dedre, 2005. The career of metaphor. Psychological Review, 112 (1), 193-216.

2. Brewer's Dictionary of Phrase \& Fable, 1999. Ed. Room, Adrian. London: Cassell.

3. Charteris-Black, Jonathan, 2014. Analysing Political Speeches: Rhetoric, Discourse and Metaphor. Basingstoke: Palgrave-Macmillan.

4. Clark, Herbert, Gerrig, Richard J., 1984. On the pretense theory of irony. Journal of Experimental Psychology: General 113, 121-126.

5. Colston, Herbert, Gibbs, Raymond W., 2002. Are irony and metaphor understood differently? Metaphor and Symbol 17, 57-60.

6. Connolly, Bernard, 1995. The Rotten Heart of Europe. London: Faber.

7. Culpeper, Jonathan, 2011. Impoliteness: Using Language to Cause Offence. Cambridge: Cambridge University Press.

8. Dynel, Marta, 2013. Irony from a neo-Gricean perspective: On untruthfulness and evaluative implicature. Intercultural Pragmatics 10(3), 403-431.

9. Fauconnier, Gilles, 1994. Mental spaces. Aspects of Meaning Construction in Natural Language. Cambridge: Cambridge University Press.

10. Fauconnier, Gilles, Turner, Mark, 2002. The Way We Think: 
Conceptual Blending and the Mind's Hidden Complexities. New York: Basic Books.

11. Fetzer, Anita, Weizman, Elda, 2015. Follow-ups across contexts and discourse domains. In E. Weizman, E., Fetzer, A. (Eds.), Follow-ups in Political Discourse. Amsterdam: Benjamins, pp. ix-xix.

12. Gibbs, Raymond W., 1994. The Poetics of Mind: Figurative Thought, Language, and Understanding. Cambridge: Cambridge University Press.

13. Gibbs, Raymond W., 2007. Experimental tests of figurative meaning construction. In G. Radden, G. Köpcke, K.-M., Berg, T. Siemund, P. (Eds.), Aspects of Meaning Construction. Amsterdam: Benjamins, pp. 1932.

14. Gibbs, Raymond W., Colston, Herbert (Eds.), 2012. Interpreting Figurative Meaning. Cambridge: Cambridge University Press.

15. Giora, Rachel, 1995. On Irony and Negation. Discourse Processes 19(2), 239-264.

16. Giora, Rachel, 2003. On our Mind: Salience, Context and Figurative Language. Oxford: Oxford University Press.

17. Giora, Rachel, Drucker, Ari, Fein, Ofer, Mendelson, Itamar, 2015a. Default Sarcastic Interpretations: On the Priority of Nonsalient Interpretations. Discourse Processes 52(3), 173-200.

18. Giora, Rachel, Givoni, Shir, Fein, Ofer, 2015b. Defaultness Reigns: The Case of Sarcasm. Metaphor \& Symbol 30: 290-313. 
19. Grice, H. Paul [1975] 1989, Logic and Conversation. In: Studies in the Way of Words. Cambridge, MA: Harvard University Press, pp. 22-40.

20. Hansard, 1991. House of Commons Debate on the European Council in Maastricht 11 December 1991 (Hansard vol. 200, cc. 859-78). http://hansard.millbanksystems.com/commons/1991/dec/11/europeancouncil-maastricht (accessed 22 January 2015).

21. Kumon-Nakamura, Sachi, Glucksberg, Sam, Brown, Mary. 1995. How about another piece of pie: The allusional pretense theory of discourse irony. Journal of Experimental Psychology: General 124, 3-21.

22. Major, John, 2000. The Autobiography. London: HarperCollins.

23. Musolff, Andreas, 2004a. Metaphor and Political Discourse. Analogical Reasoning in Debates about Europe. Basingstoke: Palgrave-Macmillan.

24. Musolff, Andreas, 2004b. The Heart of the European Body Politic. British and German Perspectives on Europe's Central Organ. Journal of Multilingual \& Multicultural Development, 25 (5 \& 6), 437-452.

25. Musolff, Andreas, 2006. Metaphor Scenarios in Public Discourse. Metaphor and Symbol, 21(1), 23-38

26. Musolff, Andreas, 2013. The heart of Europe: Synchronic variation and historical trajectories of a Political Metaphor. In Fløttum, K. (Ed.), Speaking of Europe: Approaches to complexity in European political discourse. Amsterdam: Benjamins, pp. 135-150.

27. Pálinkás, István, 2014. Blending and Folk Theory in an explanation of 
irony. Review of Cognitive Linguistics 12(1), 64-98.

28. Niemeier, Susanne, 2000. Straight from the heart - metonymic and metaphorical explorations. In: Barcelona, A. (Ed.), Metaphor and Metonymy at the Crossroads. A Cognitive Perspective. Berlin: De Gruyter, pp. $195-213$.

29. Partington, Alan, 2007. Irony and reversal of evaluation. Journal of Pragmatics 39(9), 1547-1569.

30. Partington, Alan, 2011. Phrasal irony: its form, function and exploitation. Journal of Pragmatics 43(6), 1786-1800.

\section{doi:10.1016/j.pragma.2010.11.001}

31. Recanati, François, 2004. Literal Meaning. Cambridge: Cambridge University Press.

32. Roget's International Thesaurus, 1996. Ed. Chapman, Robert. Glasgow: Roget's HarperCollins.

33. Shorter Oxford English Dictionary, 2002. Eds. Trumble, William R., Stevenson, Angus. Oxford: Oxford University Press.

34. Sperber, Dan. (Ed.), 2000. Metaprepresentations: a multidisciplinary perspective. Oxford: Oxford University Press.

35. Sperber, Dan, Wilson, Deirdre. 1981. Irony and the use-mention distinction. In: Cole, P. (Ed.), Radical Pragmatics. New York: Academic Press, pp. 295-318.

36. Wilson, Deirdre, Sperber, Dan, 1992. On verbal irony. Lingua 87, 53- 
76.

37. Wilson, Deirdre, Sperber, Dan, 2012. Explaining irony. In: Wilson, D., Sperber, D., (Eds.). Meaning and Relevance. Cambridge: Cambridge University Press, pp. 123-145. 